no such 'specialist' and in these hospitals it might be difficult to arrange proper teaching experience. For the majority of trainees the opportunity for clinical experience in liaison work is likely to be rather haphazard and competing with other clinical duties. Further. in 92 per cent of schemes self-poisoning referrals were seen either occasionally or often and so it is possible that junior staff are expected to cover this aspect of general hospital psychiatry (perhaps because senior staff are less willing to do it) and have less opportunity for other referral work. Specific links with medical teams, which would provide such opportunity for this form of referral was only available to a minority.

To improve the clinical experience and teaching of liaison psychiatry means identifying at least one consultant prepared to see part of his responsibility in this area and therefore able to properly supervise the junior staff on such referrals. It may not be possible to designate specific training posts in liaison psychiatry in most rotational training programmes, but some posts should be able to accommodate one or two days each week to liaison work. Such sessions should not get swallowed up as a convenient way of dealing with the self-poisoning cases.

There are many potential advantages to having effective liaison psychiatry services in the general hospital for patients, psychiatrists and general medical staff. To make these services effective postgraduates must be given the correct teaching. experience and support to develop the proper skills.

Leicester General Hospital

C. J. THOMAS

Leicester

\section{A suggested forum for newly-appointed consultants in child psychiatry}

\section{DEAR SIRS}

There are five components to the job of consultant: clinical. teaching. research, administrative and political. The first three are usually better taught and assimilated during our senior registrar training than are the last two. which really only begin to make sense when we take up our first post as consultant. Yet particularly in child psychiatry there are many hazards and difficulties. It seems to me that there might be some sense in newly-appointed consultant child psychiatrists meeting together regularly in their first year with senior colleagues to discuss these problems.

Child psychiatrists have more difficulties because they are very often the only member of their discipline in a District or Hospital and because they work more intimately with non-medical disciplines. I am willing to convene a monthly forum if there is enough interest. Perhaps newly-appointed consultants in child psychiatry could write to me if they are interested.

DoRa BLACK

Ro!ral Free Hospital

Hampstead, London NW3

\section{Linked or joint consultant posts in the psychiatry of mental handicap}

\section{DEAR SIRS}

In a letter to the Bulletin last year (May 1984, 8, 96), I asked readers for information about possible changing trends in appointing psychiatrists to joint/linked appointments in two different branches of psychiatry.

Nine consultants replied with information about eight specific posts. One of these was a special interest post with two sessions in mental handicap and nine in general psychiatry: three were formal joint appointments, one with seven sessions in mental handicap and four in mental illness and the other two equally divided. Four were informal joint appointments in which the majority of the work load was in the psychiatry of mental handicap and a significant minority in child psychiatry.

In addition. five senior registrars wrote or telephoned to express an interest in joint appointments or special interest posts after reading my letter.

I asked readers about the success or otherwise of such an appointment and the response was largely favourable. The only criticisms were expressed in terms of recommendations to prospective applicants; that job descriptions should be studied with care to see if the stated allocation of duties is realistically divided and will not be weighted retrospectively in one direction. The comment was made that advertisements do not always reveal that a special interest in mental handicap is required.

A view repeated by several of the correspondents was that joint appointments are a success where they are welcomed by the local general psychiatric fraternity. It was commented that joint posts are likely to be more interesting and stimulating and should attract more able applicants. with the added bonus of the support of colleagues from general psychiatry. It was also suggested that joint appointments would enable better treatment facilities for those people with mental handicap and mental illness. In addition a consultant in a linked post is in an advantageous position to have an overview of all community facilities. This overview would be made easier where linked posts enabled the catchment area of any one consultant to be reduced. The same respondent suggested that a good balance in any one district could be achieved by appointing one consultant with a mental illness background and one with a child psychiatry background. both with linked posts in the psychiatry of mental handicap. Another obvious advantage of linked posts is the increase in the number of consultants available for on-call rotas and for cover of both sick leave and holidays.

The fact that joint posts were initiated in Scotland by the 1971 Batchelor Report was referred to frequently. Such posts are commonplace in Scotland, and in the Republic of Ireland there is current interest in establishing formal joint appointments.

Another respondent argued in favour of a restructuring of specialties in psychiatry into three broad areas: general (functional) psychiatry: organic psychiatry (including 
mental handicap, psychogeriatrics and biological psychiatry): and child psychiatry (including childhood mental handicap).

Although the number of replies was small, the fact that those people who did reply all wrote enthusiastically about the success of these appointments suggests to me that Regional and District Health Authorities should actively explore the creation of linked consultant posts as one way of solving the current manpower crisis in the psychiatry of mental handicap.

St George's Hospital Medical School

London SWI7

Sheila Hollins

\section{DeAR SIRS}

The 'ivory tower' vs the 'poor nation of others'

Although there is much in $\mathrm{Dr}$ Nehama's recent article with which I can agree (Bulletin, December 1984, 8, 235-36), his title 'Academic Psychiatry versus Patient Care' implies that there is some necessary antithesis between the two. Dr Nehama argues that 'in some regions' two tiers of psychiatrists are being created. The 'approved and applauded academic elite' (who are preoccupied with teaching and research) and the vast poor nation of others (who undertake patient care). Two pages further on we have Dr Launer writing: 'Back at the ivory tower, the academic side beavers on oblivious to this catastrophe. Large numbers of doctors, psychologists, social workers and nurses in excess of regional norms, and without any extra case loads, remain aloof and busily counting their distinctions according to the number of irrelevant research papers published per year' (Bulletin, December 1984, 8, 237).

As the present incumbent of the ivory tower alluded to by Drs Nehama and Launer, let me assure them that we undertake a very great deal of patient care, and that our

TABLE I

Dr Nehama's hospital and the Ivory. Tower

Prestwich University hospital hospital of South Manchester

Resources:

Consultant psychiatrists (WTEs)

All medical staff

13.5

34.3

379

9

Psychologists

Total 'therapists'

Clinical work:

Annual admissions

Out-patient attendances

Day hospital attendances

Source: The Facilities and Services of Mental Illness and Mental Handicap Hospitals in England. Statistical and Research Reports. No 26 (1984) London: HMSO. resources compare unfavourably with those devoted to Prestwich Hospital. It is true that our staff carry out a great deal of teaching and research, but it is also true that we undertake a great deal of patient care (see Table I). The very large clinical work load on our Department does not reflect greater use by South Manchester residents of psychiatric services than residents in other areas: it is quite simply because 45 per cent of the patients served by our Unit come from elsewhere in the North-West of England to receive patient care. We are proud, Sirs, of the teaching and research activities of our Unit, and the patients vote with their feet.

DAVID GoldBerg

University' Hospital of South Manchester

West Didsbury, Manchester

\section{Self-mutilation and Klinefelter's Syndrome}

DEAR SIRS

As a researcher in the field of self-mutilation for some 12 years. ${ }^{1.2 .3} \mathrm{I} \mathrm{m}$ puzzled by the recent correspondence by Priest et al (Bulletin, July 1984, 8, 140) and Christian, Thomas and Turner (Bulletin, November 1984, 8, 218). It seems to have established, as Christian said, that 'the combination of Klinefelter's Syndrome and self-mutilation does seem to exist'. As there is no reason to suppose that Klinefelter's would lead to immunity from self-mutilation, one has no reason to doubt that the combination 'exists'. So do the combinations of self-mutilation with diabetes, ingrowing toe-nails, and a passion for crossword puzzles. We have as yet no reason whatever to regard these occasional combinations as causal or significant. The vast majority of self-mutilators do not have Klinefelter's, and the majority of Klinefelter's do not self-mutilate.

What are we supposed to make of the 'existence' of this occasional, rare combination? How does it help us to understand either condition? Various self-dominating behaviours are relatively common in the general population and probably rather more so in those of dull intelligence. Whereas specific types of self-mutilation are associated with specific genetic anomalies-such as the Lesch-Nyhan Syndrome-no one seems to be proposing that there is any particular relationship between Klinefelter's and any specific type of self-mutilation.

Why are we discussing this combination at all? Michael A. Simpson

University of Natal Medical School

Durban

REFERENCES

'Simpson, M. A. (1975) The phenomenology of self-mutilation in a general hospital setting. Canadian Psychiatric Association Journal. 20, 429-34.

2 (1976) Self-mutilation and suicide. In Suicidology: Contemporary Developments (ed. E. S. Shneidman). New York: Grune and Stratton.

3 - (1977) Self-mutilation and the borderline-syndrome. Dınamic Psychiatr!. 10, 42-48. 